\title{
Correction to: Working Overtime: Altered Functional Connectivity in Working Memory Following Regular Cannabis Use in Young Adults
}

\author{
Taylor Hatchard $^{1,2} \cdot$ Aziza Byron-Alhassan $^{1} \cdot$ Ola Mioduszewski $^{1}$ • \\ Katherine Holshausen ${ }^{2}$ - Stacey Correia ${ }^{2}$ - Allison Leeming ${ }^{1} \cdot$ Gladys Ayson $^{1}$ • \\ Carley Chiasson ${ }^{1} \cdot$ Peter Fried $^{3} \cdot$ Ian Cameron ${ }^{4} \cdot$ Andra Smith $^{1}$ (D)
}

Published online: 4 April 2020

(C) Springer Science+Business Media, LLC, part of Springer Nature 2020

The online version of the original article can be found at https://doi.org/10.1007/s11469-020-00226-y

\author{
Andra Smith \\ andra.smith@uottawa.ca \\ Taylor Hatchard \\ thachar@stjosham.on.ca \\ Aziza Byron-Alhassan \\ abyro025@uottawa.ca \\ Ola Mioduszewski \\ miod087@uottawa.ca \\ Katherine Holshausen \\ kholshau@stjosham.on.ca \\ Stacey Correia \\ corres5@mcmaster.ca \\ Allison Leeming \\ aleem056@uottawa.ca \\ Gladys Ayson \\ gayso088@uOttawa.ca \\ Carley Chiasson \\ Cfall041@uottawa.ca \\ Peter Fried \\ peter_fried@carleton.ca \\ Ian Cameron \\ icameron@toh.ca
}

Extended author information available on the last page of the article 


\section{Correction to: International Journal of Mental Health and Addiction https://doi.org/10.1007/s11469-020-00226-y}

The caption for Fig. 1 was incorrect in this article as originally published.

The correct caption is:

Fig. 1 Regions of the brain where cannabis users had significantly more activity than the nonusers during working memory. Blue crosshairs in a) are located on the most significantly different voxel of the left superior temporal gyrus (x,y,z $=-63-245, \mathrm{~T}=4.99, p<0.001)$ and the right middle temporal gyrus $(\mathrm{x}, \mathrm{y}, \mathrm{z}=66-27-10, \mathrm{~T}=4.63, p<0.001)$. Blue crosshairs in $\mathrm{b})$ are localized to the most significantly different voxel of the right medial superior frontal gyrus $(\mathrm{x}, \mathrm{y}, \mathrm{z}=125130, \mathrm{~T}=4.02, p<0.001)$

The article has been updated.

Publisher's Note Springer Nature remains neutral with regard to jurisdictional claims in published maps and institutional affiliations.

\section{Affiliations}

Taylor Hatchard $^{1,2} \cdot$ Aziza Byron-Alhassan $^{1} \cdot$ Ola Mioduszewski $^{1} \cdot$ Katherine $^{2}$ Holshausen $^{2}$ - Stacey Correia ${ }^{2}$ - Allison Leeming ${ }^{1} \cdot$ Gladys Ayson $^{1} \cdot$ Carley Chiasson $^{1}$. Peter Fried $^{3} \cdot$ lan Cameron ${ }^{4} \cdot$ Andra Smith $^{1}$

1 School of Psychology, University of Ottawa, 136 Jean Jacques Lussier, Ottawa, ON K1N-6N5, Canada

2 Department of Psychology, St. Joseph's Healthcare Hamilton, 100 West 5th Street, Hamilton, ON, Canada

3 Department of Psychology, Carleton University, 1125 Colonel By Drive, Ottawa, ON K1S-1S2, Canada

4 Department of Diagnostic Imaging, The Ottawa Hospital, 1053 Carling Ave, Ottawa, ON K1Y-4E9, Canada 